\title{
Las manos sucias de la Teoría Crítica: Adorno y Habermas ante el eje teoría-praxis ${ }^{1}$
}

\author{
Marina Hervás Muñoz
}

\begin{abstract}
Resumen: Este trabajo lo componen dos partes: la primera, donde se analiza la reconstrucción de las diferentes formas de comprensión del eje teoría-praxis en la tradición filosófica a juicio de Habermas; y la segunda, en la que se plantea la crítica al respecto de Habermas a su mentor, Adorno. Las objeciones de Habermas se concentran en la, a su juicio, reducción de la racionalidad a lo instrumental, a lo que opone su modelo de acción comunicativa. Se tratará de mostrar algunos problemas de tal crítica y analizar cómo la filosofía de Adorno no consiste, como en Habermas, en reformular la racionalidad, sino de relativizar su fuerza.
\end{abstract}

Palabras clave: J. Habermas; T. Adorno; Teoría-praxis; Racionalidad; Acción comunicativa.

The dirty hands of critical theory: Adorno and Habermas in the face of the theorypraxis axis

Abstract: This paper is divided in two parts: first, an analysis of the Habermasian reconstruction of the different ways of comprehending the axis theory-praxis in the philosophical tradition; and second, a consideration of the Habermasian criticism on Adorno's thought in that regard. Habermas' objections are focused on the alleged reduction of rationality to its instrumental character, to which he opposes his model of communicative action. I will then highlight some of the problems of these objections and analyze how Adorno's philosophy is not concerned - like Habermas' - with the reformulation of rationality, but rather with lessening its power.

Key words: J. Habermas; T. Adorno; Theory-praxis; Rationality; Communicative action.

\footnotetext{
${ }^{1}$ Recibido el 14/08/2016 y aprobado el 30/11/2016.

${ }^{2}$ Doctoranda en Filosofía por la Universidad Autónoma de Barcelona (UAB), España. Contacto: mhermu@hotmail.com.
} 
$|134|$

Las manos sucias de la Teoría Crítica:...

As mãos sujas da teoria crítica: Adorno e Habermas ante o eixo teoria-práxis

Resumo: Este trabalho é composto por duas partes: a primeira, na qual se analisa a reconstrução das diferentes formas de compreensão do eixo teoria-práxis na tradição filosófica sob a perspectiva de Habermas; e a segunda, na qual se considera a crítica de Habermas ao seu mentor, Adorno, a este respeito. As objeções de Habermas se concentram na redução, segundo seu juízo, da racionalidade ao instrumental, ao que opõe seu modelo de ação comunicativa. Tratar-se-á de mostrar alguns problemas de tal crítica e analisar como a filosofia de Adorno não consiste, como em Habermas, em reformular a racionalidade, mas antes em relativizar sua força.

Palavras-chave: J. Habermas; T. Adorno; Teoria-práxis; Racionalidade; Ação comunicativa.

En una conferencia impartida en un congreso celebrado en Berlín a principios del año 2016, García-Dütmann reflexionaba sobre si los filósofos podían tener "las manos sucias", tomando prestado el título de una obra de teatro de Sartre. Se preguntaba, de nuevo, si la filosofía tiene implicación práctica y, en caso afirmativo, de qué naturaleza es. También de mancharse las manos hablaba Adorno en su texto "Resignación" (ADORNO, 2008). ${ }^{3}$ Este tema ha sido central en casi toda filosofía práctica desde el mismo origen de la disciplina y encontró uno de sus puntos más críticos en el seno de la "vieja" Teoría Crítica. Sus miembros encontraron en este asunto un lugar de discordia: ante las protestas estudiantiles del curso 1967-1968, Adorno y Horkheimer se decantaron por el "nicht-mitmachen", mientras que Marcuse apostaba por lo que podríamos llamar el "(doch)-mitmachen" (Cfr. FEENBERG, 2015, p. 127). ${ }^{4}$ Para muchos, especialmente los estudiantes que se manifestaron durante el curso 1968-1969, la postura de Adorno y Horkheimer fue una verdadera decepción, pues precisamente las lecturas y clases de sus teorías les habían impulsado a salir a

\footnotetext{
${ }^{3}$ Siempre que ha sido posible, he optado por poner las traducciones existentes al castellano de la bibliografía.

${ }^{4}$ El concepto de "Mitmachen" es un tanto complicado de traducir al español. Algunos traductores y autores optan por "participar" o "participación", mientras que otros se deciden por "entrar en el juego".
} 
las calles (y a ocupar el propio Instituto de Investigación Social). Debido al rechazo de la "práctica revolucionaria", muchos críticos han asumido ahí un punto de inflexión entre la fuerza de la teoría crítica y la imposibilidad de su práctica. En este texto propongo revisar la construcción del marco sobre la cuestión teoría-praxis que Habermas realizó en varios lugares de su obra, así como resituar el concepto de "nicht-mitmachen". Habermas consideraba que Adorno y él coincidían en sus "impulsos filosóficos básicos" (DEWS, 1992, p. 220) y que convergían en la crítica a la praxis y, especialmente, con respecto al rechazo al activismo. Excede los límites de este artículo la profundización en el significado de "teoría" y "praxis". Sin embargo, sí parece fundamental que sea explícito que "praxis" no se reduce a "activismo", ni a "organización o participación política" (el engagement), ni necesariamente a procesos más o menos revolucionarios de generación de nuevas o contrainstituciones. Se trata, más bien, de ver cómo la teoría puede llegar a ser realidad. Por tanto, el concepto de "praxis" que se maneja aquí tiene más que ver con la pregunta por la relación de la utopía, de si lo que la teoría exige y lo que de hecho sucede en lo real podrían llegar a coincidir en todos los ámbitos de la existencia (también, claro, el político). En este artículo me propongo analizar, en la primera parte, los derroteros que ha seguido la relación teoría-praxis según Habermas y, en el segundo, marcar las líneas fundamentales de las divergencias entre Habermas y su profesor, Adorno, al respecto.

\section{Pequeña historia del eje teoría-praxis según Habermas}

Según Habermas, la relación entre teoría y praxis ha experimentado al menos cuatro grandes fases: (a) la primera de ellas, la planteada por Platón, que señala que "no hay nada más práctico que la propia teoría" (HABERMAS, 2002, p. 306). La característica fundamental que Habermas encuentra es que el eje platónico de teoría-praxis no se mide con lo epistemológico sino que, a su juicio, conserva un elemento teológico o, dicho en sus términos, de "salvación". Esta salvación se tematiza en la "purificación", algo que se evidencia, por ejemplo, en la 
| 136 |

Las manos sucias de la Teoría Crítica:..

explicación sobre la belleza que lleva a cabo Diotima en El banquete o el proceso de reencarnación que cierra La República (617d-621d). La praxis no se entiende como una "ejecución" de la teoría o como "otra forma" de hacer teoría, el centro no es epistemológico, sino que se dirige hacia la consecución de una "vida buena" futura. La diferencia que Habermas señala entre la religión y la filosofía es su público: la praxis de la filosofía en términos platónicos se restringe al sabio, al "filósofo rey", mientras que la religión tenía un sentido omniabarcante, masivo. Tal elemento elitista se conserva en la filosofía, por más que se hayan hecho arduos intentos de superarlo.

Según Habermas, Heidegger recupera en cierto modo la forma arcaica de salvación aunque secularizada. Heidegger, a su juicio, trata de "superar la autocomprensión humanista de la modernidad" y su proyecto "recuerda al sentido originariamente religioso de la contemplación" (HABERMAS, 2002, p. 313). También toma la figura elitista del pensador que tiene un "acceso privilegiado al acontecer de la verdad" (Ibídem). El centro de esta crítica, en realidad, se encuentra en la Jerga de la autenticidad adorniana. Adorno, sin embargo, es mucho más radical que Habermas en este asunto. Para él, mientras la salvación en Platón era por así decirlo el motor del conocimiento, su motor, en Heidegger, es la falsa figura de una catástrofe que "se expresa como si fuera la salvación" (ADORNO, 2005, p. 396).

Paulatinamente, la filosofía va dejando a un lado esta tendencia hacia la salvación y se va configurando como corpus epistemológico (b). La distancia entre teoría y praxis o, mejor dicho, la primacía de lo teórico, sin embargo, se mantiene. Este giro epistemológico se da de dos formas esencialmente: por un lado (i), en la reconfiguración aristotélica, la teoría se dirige hacia la configuración de "la vida buena" sin salvación, algo que implica la "renuncia a la certeza del saber teórico" y la pérdida de motivación que "debe presuponer ya en aquellos a quienes se dirige un carácter adecuadamente constituido" (HABERMAS, 2002, p. 308-309). Por otro lado (ii), la persistencia heredada en la desconfianza por lo empírico, por lo "meramente" práctico, se encuentra a la base de 
los primeros intentos epistemológicos, que hacen que se dividan las formas de conocer en "verdades de hecho" y "verdades de razón". La incapacidad de algunas disciplinas de desarrollar una teoría en un sentido enfático les hacía caer en el desprestigio de ser consideradas como meras disciplinas empíricas: tal era el destino de la geografía o la historiografía, que servían para describir lo empírico, pero no para "elevarse" por encima de ello. Se configuran así dos ejes de teoría-praxis: el epistemológico, que atiende a las relaciones de correspondencia entre la realidad y el concepto de "verdad"; y el ético, donde la correspondencia se analiza entre un concepto de "bien" y la acción humana. Habría, de nuevo, dos alternativas: la ética formal, aquella que trata de configurar principios, "condiciones y modalidades para una dirección de la vida consciente y auténtica", que llevan a "una vida ejemplar públicamente aceptada" (HABERMAS, 2002, p. 309). El modelo de ética moderno, en concreto, "[d]esde Kant y Kierkegaard", continúa Habermas, "dirige al individuo privado el consejo de que con fin de conducir su vida con autenticidad introduzca en ella una determinada forma de reflexión" (Ibídem). Por tanto, ya no está en el centro de la cuestión la vida buena "para mí" sino a la "vida común justa que sea buena para todos por igual" (HABERMAS, 2002, p. 310). Es decir, se entiende que el individuo solo podrá desarrollarse enfáticamente como tal en la medida en que se integre "adecuadamente" en la sociedad y que se garanticen las condiciones en las que pueda ejercer su libertad. La razón, entonces, se convierte en el elemento regulador. Si se pueden delinear los derroteros de lo que sería una sociedad racionalmente deseable o, dicho en términos estrictamente modernos, la "mejor sociedad posible", parecería que el objetivo primordial consistiría en trazar las líneas de constitución de tal modelo racional dentro de la razón individual. Es decir, que la razón individual debería ser capaz de adaptarse a "la intelección de lo que es bueno para todos" (Ibídem), que, en Hegel, adopta la forma del Estado, en tanto entidad representativa de "lo bueno para todos racionalmente" o, en sus términos, "la rica articulación de la moral en sí" (HEGEL, 2000, p. 69). La filosofía se dedicó a configurar cómo debía ser 
| 138 |

Las manos sucias de la Teoría Crítica:...

ese modelo intelectivo al que la razón debía asemejarse, pero no encontró la forma práctica de que se hiciera efectiva tal semejanza, la tensión que en Hegel aparece cifrada entre "norma racional y realidad irracional".

A continuación, Habermas encuentra en el siguiente estadio una nueva división, en la que la teoría se convierte en "falsa conciencia" y en "crítica" (c). Es decir, se rompe con la clásica confianza en la teoría y también comienzan a resquebrajarse los principios de la razón. Este momento lo sitúa en Marx y en Feuerbach que, a su juicio, "criticaron la forma idealista de su filosofía [de Hegel] pero quisieron conservar su contenido racional" (HABERMAS, 2002, p. 310). Para el marxismo, según la interpretación habermasiana, la explicitación de que la teoría es falsa conciencia, es decir, la diagnosis de las aporías que surgen de la totalización de la razón y su crítica, permitiría la conversión de la teoría en "praxis liberadora". Habermas hace entonces una distinción entre tipos de teoría que habita la filosofía. Por un lado, las "disciplinas ascéticas" se concentrarían en los propios problemas, digamos, "internos" de la filosofía ("pensamiento exotérico"); mientras que el "pensamiento esotérico" se encargaría de la reflexión sobre aspectos que no derivan de pero afectan a la filosofía. Para Habermas, lo exotérico surge en la medida en que la modernidad necesita una "autocomprensión normativa" (HABERMAS, 2002, p. 312). En lo esotérico es donde se incluye, a su juicio, el marxismo, en la medida en que la teoría no tiene interés per se, sino en tanto que puede dirigir la praxis. En esta división, parece que Habermas no está teniendo en cuenta algo que Adorno tuvo muy claro durante toda su vida: que no hay tal división entre lo "interno" y lo "externo" a la filosofía, de ahí que en su texto "Sobre sujeto y objeto", al final de su vida, afirmase que "crítica de la sociedad es crítica del conocimiento y viceversa" (ADORNO, 1993, p. 149). Es decir, que las formas de la filosofía se encuentran profundamente afectadas por la estructura social en las que se desarrollan, pero también al revés. Parece que Habermas no toma en consideración este momento dialéctico de la configuración entre modelos de crítica pues, para él, la teoría tiene 
una doble vía diferenciada: "el contexto histórico de constitución de una situación de intereses a la que aún pertenece la teoría" y "el contexto histórico de acción sobre el que la teoría puede ejercer una influencia que orienta [tal] acción" (HABERMAS, 1987, p. 13-14).

El punto desde donde surge la filosofía de Benjamin, de Adorno y de Horkheimer es en la conversión de la desconfianza en la naturaleza en su sometimiento por parte de la razón. Horkheimer lo diagnostica como un "antagonismo entre el yo y la naturaleza" (HORKHEIMER, 1973, p. 171). También consideran una repetición del idealismo considerar que la teoría se puede convertir en praxis liberadora, pues como dice Adorno, invirtiendo a Marx, la filosofía no es que haya dejado de transformar el mundo por dedicarse a interpretarla, sino que la ha interpretado insuficientemente (cfr. ADORNO, 1984, p. 11). Para Adorno y Horkheimer, especialmente, el modelo marxista sigue confiando, en realidad, en la posibilidad de generar un modelo racional que dirija la praxis. Precisamente, según Adorno, "la filosofía [...] sigue viva porque se dejó pasar el momento de su realización" (Ibídem). Es decir, en el fondo, el marxismo mantenía la confianza en un concepto enfático de teoría, en tanto aparato regulador de la praxis. Adorno, además, fue muy crítico con el modelo socialista del bloque del este. Para él, en ese contexto, "cuando en el ensalzado binario teoría-praxis perdió la teoría, la praxis se convirtió en irracional y en parte de esa política que quiera superar; es decir, quedó a merced del poder. La liquidación de la teoría a base de dogmatizar y que prohíbe el pensamiento contribuyó a la mala praxis" (ADORNO, 1984, p. 47). Para Adorno, este desplazamiento es, precisamente, la constatación de que "los objetos son más que su concepto", es decir, de que la teoría siempre es menos de lo que promete y de que cualquier intento de hacer que teoría y praxis coincidan repite el modelo idealista en que la realidad es capaz de repetir lo meramente pensado en la razón.

En este punto coincidiría la crítica de Habermas a la tradición marxiana, que él detalla en tres puntos. Por un lado, al igual que sus maestros de la Teoría Crítica, considera que no se ha abandonado la pretensión de totalidad. Para él, "solo [se han] transferido 
| 140 |

Las manos sucias de la Teoría Crítica:...

las figuras del pensamiento teleológicas desde la naturaleza al conjunto de la historia mundial" (HABERMAS, 2002, p. 311). Por otro, rechaza lo que él considera "sujetos de gran formato", a saber "'clase social', 'cultura', 'pueblo' o 'espíritu de los pueblos'”. Su intención, entonces, consistiría en repensar la figura del sujeto hacia lo particular y desde la configuración de procesos intersubjetivos. El último punto de la crítica de Habermas a la teoría marxiana se concentra en la contraposición entre el sujeto que consideraba como "de gran formato" frente al sujeto particular. La promesa de un mundo que llegará y será mejor para todos los sujetos particulares, articulada por una entidad superior, ha quedado desacreditada por los reiterados intentos fallidos de gobierno que abanderaban la revolución social. En el trasfondo de esta premisa se encuentra, entonces, un momento fundamentalmente elitista, en que una entidad ajena a los sujetos particulares sabe lo que de hecho es mejor y más conveniente para ellos, además del camino para alcanzarlo. Habermas, además, lo analiza lingüísticamente. Desde su punto de vista, tal sujeto "de gran formato" estaría en la disyuntiva del "sí" o del "no", pero no ante la "condición pluralista" que presentan los sujetos particulares.

En tal tendencia, Habermas coincide con la primera Teoría Crítica. La cuestión sobre el "ser humano" [Mensch] es tan antigua como la propia filosofía, ya sea por marcar ideológicamente la separación entre "lo animal" y "lo humano", una división que deriva de la que opone "natura" y "cultura", o por poder atribuir, a ese conjunto llamado "humanos", determinadas consecuencias morales de sus actos, algo que proviene, en realidad, de la asunción de que el humano, a diferencia de otras formas de existencia, es racional y, por tanto, actúa siguiendo una lógica por lo que sus actos se pueden medir según la estructura causa-efecto. Ambos momentos de la definición del hombre son, a lo largo de la historia de la filosofía, matizados, ampliados, modificados. El concepto del ser humano marca la filosofía europea durante la segunda guerra mundial y su posguerra, en la época en que ya no cabía optimismo alguno para comprender al hombre, devenido en cosa. La crítica de 
Adorno a la praxis también se incardina en torno a la categoría de "ser humano" y su relación la colectividad. Al igual que la crítica a la democracia de Rousseau o de Kant, para Adorno la colectividad reprime la espontaneidad individual y tiende a la igualación de lo diferente. Al igual que en su teoría del conocimiento Adorno critica duramente la totalidad y propone algo así como una "totalidad abierta", donde ésta no sea una mera suma de partes, sino que se mida siempre con aquello que trata de captar absolutamente a través de la fuerza de sus partes; en la tensión individuo-colectivo aparece la misma necesidad de trazar una colectividad abierta, en la que el sujeto particular no se disuelva en lo colectivo. El concepto de "nosotros" tiene para Adorno, tal y como desarrolla en sus textos sobre estética, un anclaje en lo mítico, en los modelos arcaicos de colectivización y disolución del individuo. Para Adorno, tanto el sujeto como el colectivo experimentan un proceso de represión en las sociedades modernas, tanto para sí mismos como en mutua relación. En Adorno, tal como detecta Wellmer, se da una aporía: "así como la transformación de la naturaleza externa genera la posibilidad objetiva para una sociedad liberada, la transformación simultánea de la naturaleza interna destruye las posibilidades subjetivas de la praxis emancipatoria" (WELLMER, 1990, p. 29). Pero también sucede al revés: cuando un sujeto es idéntico a sí mismo, le coacciona la identidad. Por eso, en Adorno se encuentran numerosos momentos en los que defiende la "soledad" del individuo: para él, "el 'discurso solitario' dice más de la tendencia social que el comunicativo" (ADORNO, 2011, p. 46). Mientras uno de sus alumnos más brillantes, H-J. Krahl, consideraba en 1971 que el nicht-mitmachen era, en Adorno, expresión del sujeto burgués, según Habermas es precisamente tal sujeto el que da la clave para comprender "el privilegio de la experiencia [...] que tienen que presuponer [Adorno y Horkheimer] para enfrentarse al atrofiamiento de la subjetividad contemporánea", en la medida en que el sujeto burgués se encuentra "en trance de desaparición" (HABERMAS, 1975, p. 152-153). De su "deshilachada sustancia" toman Adorno y Horkheimer el material para su protocolo sobre el sujeto y la coacción social que lleva a su "liquidación". Honneth 
| 142 |

Las manos sucias de la Teoría Crítica:..

señala que "la idea de un universal racional de la autorrealización cooperativa" la "comparten sin excepción todos los miembros de la Teoría Crítica" (HONNETH, 2009, p. 35). Como mostraremos al final del texto, la diferencia entre Habermas y Adorno se encuentra precisamente en la concepción de esta "autorrealización cooperativa" o, en otros términos, del cumplimiento de las promesas de la ilustración.

El siguiente estadio que Habermas encuentra en la relación que nos ocupa, la de teoría-praxis en la filosofía, es aquella que la hace medirse con la ciencia (d). Para Habermas, la filosofía, primero una con la ciencia, hasta el siglo XVII, ha dejado paulatinamente de lado la fatigosa labor de estar "frente" a las ciencias para "situarse dentro de ese mundo por ella interpretado" (HABERMAS, 2002, p. 313). Esto hace que, según su criterio, la filosofía se tenga que enmarcar en una red constituida por "cultura, sociedad y persona, así como la esfera pública y privada del mundo de la vida" (HABERMAS, 2002, p. 314). Es decir, Habermas entiende que la especialización del conocimiento hace necesario acotar los espacios donde la filosofía aún tiene algo que decir. Eso no le hace caer, empero, en un concepto estrecho de filosofía y asume su inatrapabilidad: "la filosofía no puede identificarse completamente con ninguno de sus papeles; solo puede desempeñar un determinado papel en la medida en que, al mismo tiempo, trasciende de éste" (Ibídem). Para él, la filosofía ha ido adoptando, según las ciencias particulares han ido encontrando su acomodo en los saberes, un papel que es aglutinador pero al mismo tiempo no reduccionista. Esto es, la filosofía en términos contemporáneos se caracterizaría por tres elementos: i) por su colaboración con otras ciencias, ii) como herramienta conceptual para "teorías empíricas con planteamientos fuertemente universalistas" y iii) como disciplina de estudios interna del derecho, la moral y el arte, algo que Habermas interpreta, en última instancia, en términos lingüísticos; es decir, como una disciplina capaz de "pasar de un lenguaje a otro y traducir el lenguaje especial de una [disciplina] en el lenguaje especial de la otra" (HABERMAS, 2002, p. 315). Parece que Habermas no toma en cuenta, curiosamente, 
la especificidad del lenguaje de la filosofía que haría, en realidad, que la filosofía tradujese el lenguaje especial de una disciplina en el especial de la filosofía, algo que hace, entre otras cosas, que aún se la considere como algo distinto a la teoría sobre aquello de lo que se ocupa. Por tanto, la consideración habermasiana de que la filosofía tiene como "rasgo específico" "la pluralidad de lenguajes" que le permite "preservar la unidad de la razón" (Ibídem) parece que adolece de un concepto moderno de razón, en el cual ésta debe guardar su "unidad" y a la filosofía en una especie de cajón lingüístico que amalgama las diferencias - de momento solo lingüísticas - de las ciencias particulares. En otros términos, parecería que aquí Habermas prima el carácter formal de la filosofía, haciéndola incapaz de generar un tipo de conocimiento específico y distinto del resto de disciplinas. La filosofía, entonces, sería enfáticamente auxiliar. Para Habermas, los intelectuales que se dedican a la filosofía solo en situaciones límite pueden asumir el rol de "expertos". La otra función práctica de la que dota a la filosofía es la de "mediadores de sentido", que convierte al filósofo en un asesor para "alentar al individuo a dirigir de forma consciente su propia vida" (HABERMAS, 2002, p. 317), pese a que asume que la filosofía no ha sido capaz de resolver cuestiones que antes ocupaban a la religión, como la muerte o los elementos fundamentales de la existencia, como la felicidad, aunque sí parece la disciplina específicamente articulada para dedicarse a pensar sobre ello. La fuerza de la ciencia por tanto, según Habermas, afecta al alcance y labor de la filosofía: "si hubiera de existir una filosofía ante la que ya no se planteara la cuestión de para qué seguir con la filosofía, habría de tratarse hoy [...] de una filosofía no cientifista de la ciencia" (HABERMAS, 1975, p. 33). Habermas no concibe la contradicción en la que incurre una filosofía que no se pregunta por sí misma: una filosofía antifilosófica con su propio cometido. Quizá, el problema es que la respuesta siga siendo demasiado incómoda.

En las "sociedades tardocapitalistas" hay, para Habermas, tres aspectos fundamentales en la relación teoría-praxis, que se concentran en la empiria, la epistemología y la metodología. Su 
análisis parte, en el ámbito de la empiria, de un núcleo grueso de "población despolitizada" que surge por la "tecnocratización" de la política, en la medida en que ésta ya no parece que emerge de una suerte de abstracta voluntad del pueblo, sino de decisiones macroestructurales, las cuales no pueden ser omniabarcadas por la opinión del individuo particular por su complejidad y magnitud. Para el ámbito de la empiria, parte de sus trabajos de juventud sobre la publicidad y la opinión pública, en los que constata que ambas ya no centran su interés en crear estrategias de sumisión sino en el "control de la lealtad". Una de las preguntas clave de este aspecto seria la siguiente: “'han emigrado los motivos configuradores de la conciencia desde un punto de vista político del ámbito del trabajo productivo" - como sugería Marx - "a otros ámbitos del sistema ocupacional?" (HABERMAS, 1987, p. 18). El aspecto epistemológico lo concentra en el eje "conocimiento e intereses". Habermas critica que el problema del conocimiento suele ser pasado por alto en los análisis de las encrucijadas entre teoría y praxis. La clave está en dilucidar cómo los intereses, sean de la naturaleza que sea, intervienen en la constitución del conocimiento. Por tanto, hay una doble relación entre teoría y praxis en el conocimiento: la que se da dentro de las propias disciplinas, es decir, interna, pero también la externa, aquella que configura el marco en el que se desarrollan tales disciplinas o, en términos habermasianos, las "objetivaciones de la realidad" que les sirven de fundamento. Por último, Habermas se encarga del aspecto metodológico, en las que se toma en cuenta cómo se articula la investigación en un marco crítico, es decir, donde se explicitan los problemas de su contexto al mismo tiempo que se está inserto en él.

\section{Acorralamiento de la razón: divergencias entre Habermas y Adorno}

Con la reconstrucción de la relación entre teoría y praxis, Habermas pretende, entre otras cosas, resituar el modelo ofrecido por Adorno. Para Habermas, Adorno reduce el eje teoría-praxis a la constatación de que el paulatino control de la naturaleza 
externa implica la también paulatina opresión de la interna. La crítica habermasiana al frankfurtiano se concentra, al menos, en tres momentos: (i) la reformulación del lugar de la filosofía; (ii) la confrontación entre la racionalidad instrumental y la comunicativa y (iii) el modelo de la autoilustración.

Según Patrick J. Deneen, Adorno es más platónico que Platón en la medida en que "critica las llamadas a la participación [Mitmachen] precisamente porque tal actividad política interfiere en la pureza de la contemplación [...] de la razón crítica" (DENEEN, 2000, p. 200, mi traducción). Es decir, siguiendo el marco habermasiano, parecería que la participación ensuciaría, por así decirlo, el aura de lo teórico. Este análisis incurriría en un momento antiadorniano en la medida en que pasaría por alto la comprensión dialéctica de lo teórico. El nicht-mitmachen adorniano tiene que ver con dos elementos: por un lado, con la explícita distancia que Adorno toma con respecto a la lógica de partidos. De hecho, buena parte de su Dialéctica negativa se concentra en construir una oposición al supuesto bloque socialista alemán, y a mostrar sus contradicciones con un modelo verdaderamente de izquierdas. Por otro lado, y siguiendo los argumentos que se han delineado supra, en Adorno "la teoría y la praxis política son no-idénticas y su relación está altamente mediada" (BUCK-MORSS, 1977, p. 31, mi traducción). La no-coincidencia entre teoría y praxis política, en realidad, va en paralelo a la exigencia de no-coincidencia de ambos polos en la teoría del conocimiento. Según Adorno, la multiplicidad de lo real implica la revisión constante de las formas del conocer. Conocer es, por tanto, una "derrota preestablecida". Por eso, uno de los objetivos de su teoría del conocimiento es llenar de historia el concepto de verdad y rechazar diametralmente cualquier gesto de philosophia perennis. De este modo, uno de los dictums centrales de su Dialéctica negativa es lo que considera como "utopía del conocimiento": "penetrar con conceptos lo no conceptual sin acomodar esto a aquellos" (ADORNO, 1984, p. 18). Lo mismo sucede con la teoría y la praxis: para él, "el concepto enfático de pensar no es congruente ni con las situaciones existentes, ni con los fines a alcanzar, ni con batallones sean cuales sean. Lo que una 
| 146 |

Las manos sucias de la Teoría Crítica:...

vez fue pensado puede ser reprimido, olvidado, arrastrado por el viento" (ADORNO, 2008, p. 712). Para Habermas, sin embargo, la aceptación de la imposibilidad de desarrollar, como en la tradición, una prima philosophia, la ratificación de lo histórico de las categorías otrora aceptadas como punto inicial, como base de la filosofía, impiden que la filosofía continúe calificándose como tal. Su "autofundamento" y su "autocumplimiento" es incapaz de alcanzarlo "qua filosofía": deberá hacerlo "qua unidad de teoría y praxis" (HABERMAS, 1987, p. 410). Aquí encontramos, por tanto, el núcleo del primer aspecto (i), la reformulación de la filosofía. En este punto nunca podrán converger Adorno y su no-discípulo Habermas (Cfr. CLAUSSEN, 2006, p. 345), pues, para Adorno, "el pensar abierto", en tanto "punta más allá de sí mismo [e]s un comportamiento, una forma de praxis" (ADORNO, 2008, p. 712), por lo que la filosofía, la teoría, para Adorno, es ya praxis y lo que se le opone es, más bien, ideología. Lo que Adorno defiende, como luego desarrolla en Dialéctica negativa, es que la praxis "es un concepto eminentemente teórico" $y$, por tanto, para él, no existe una pura primacía de la praxis como, por ejemplo, exigiría el activismo.

Habermas fue uno de los primeros críticos del concepto de razón de Adorno al señalar que "pese a la radicalidad de su crítica de la razón", su proyecto no consiguió distanciarse verdaderamente del concepto de razón de los grandes filósofos de la tradición (Cfr. DEWS, 1992, p. 215). Por eso, Habermas concentra su crítica en el acorralamiento de la razón instrumental de Adorno y Horkheimer (ii). Para él, la razón instrumental sigue dentro del mismo paradigma en el que se encontraban los cuatro puntos que hemos desarrollado hasta ahora en el análisis del eje teoría-praxis: la estrategia "cognitivo-instrumental". Por eso, su propuesta se dirige a incluir tal estrategia en el análisis de algo por encima de ella: la "acción comunicativa". Para él, "el fenómeno que hay que explicar no es ya el conocimiento y sojuzgamiento de una naturaleza objetivada tomados en sí mismos, sino la intersubjetividad del entendimiento posible" (HABERMAS, 1999, p. 499). Por tanto, surgen dos modelos de relación con el mundo: "incremento 
del saber sobre el mundo objetivo" y "una solución justa de los conflictos de interacción" (HONNETH, 2009, p. 41). Esto eliminaría, de un plumazo, buena parte del diagnóstico de crítica a la cultura de la "vieja" Teoría Crítica, en la que no hay saber "objetivo del mundo" verdadero que no piense, a su vez, de lo justo de ese conocer, $\mathrm{o}$, dicho en términos abstractos, donde no se explicite la relación entre forma y contenido. Habermas, entonces, desplaza el "problema central de la filosofía", a saber, la racionalidad, al hecho de que el saber - racional o no - tiene una estructura proposicional $\mathrm{y}$, por tanto, los análisis realizados por Adorno (y Horkheimer) sobre la racionalidad instrumental remitirían necesariamente a lo lingüístico. Según Habermas, para Adorno y Horkheimer "el mundo no adolece de un exceso de razón, sino más bien de un importante déficit en su aplicación" (VELASCO, 2014, p. 24). Como explica Habermas, la "manipulación instrumental" de la razón sería solo un tipo de "utilización del saber proposicional", que se relaciona con el del "entendimiento comunicativo" (HABERMAS, 1999, p. 29). Para él, que la Teoría Crítica siguiese arguyendo sus argumentos con base en la filosofía de la historia fue lo que impidió su avance. Su gesto se traduce en la reformulación de la "razón instrumental" hacia la "razón comunicativa". Habermas concentra su revisión de la crítica a la razón en la Dialéctica de la ilustración a un error de base: la equiparación entre dominación y racionalidad (pretensión de poder y pretensión de validez) que llevarían a los filósofos frankfurtianos a un punto de no-retorno. Para Habermas, en el fondo se esconde en esta equiparación el momento ideológico que considera que la razón podrá "purificarse", que podrá pulir lo peor que ha adquirido por lo empírico (Cfr. HABERMAS, 1993, p. 162).

Parece que la clave para cifrar la relación entre Habermas y Adorno se encuentra en el gesto de lo comunicativo. Mientras para Adorno la comunicación es siempre una adaptación, otra forma de reducir conceptualmente la multiplicidad de lo real, para Habermas es la forma de desacorralar a la razón de su tendencia a la dominación. Habermas traza la encrucijada de la teoríapraxis del especialista en filosofía con una pregunta: “¿cómo son 
| 148 |

Las manos sucias de la Teoría Crítica:...

posibles las ideas radicales y las doctrinas de graves consecuencias políticas y que, así y todo, el filósofo ni extralimite su moralizante responsabilidad [...] ni se entregue a una irresponsabilidad objetiva?" (HABERMAS, 1987, p. 19). También, al igual que Adorno hizo con su "no hay vida correcta en lo falso" de su Mínima moralia, Habermas constata la desviación que supone la filosofía con respecto al desarrollo capitalista. En Adorno, la teoría debería articular el análisis de eso "falso", pero parecería que cualquier intervención simplemente repetiría la falsedad. Es, en realidad, una articulación de un problema al que se enfrentan todos los activistas que rechazan el modelo capitalista. Su fuerza, su capacidad de ser "espíritu hecho vientre", es decir, su tendencia a fagocitar lo aúnno-integrado, hace que cualquier acción anticapitalista se convierta en capitalista y que, además, le ofrezca un nuevo producto. Por eso, Adorno señala que el "practicismo" [Praktizismus] puede llegar a ser una "praxis represiva y opresiva" (ADORNO, 1997, p. 14, mi traducción). J. G. Finlayson señala la aporía en la que incurre Adorno: "bajo las condiciones actuales, no solo no podemos vivir correctamente, sino que no podemos ni siquiera concebir qué sería vivir ética y moralmente la vida correcta" (FINLAYSON, 2015, p. 62, mi traducción). Pero, de hecho, Adorno va más allá. Para él, "el horror se encuentra en que por primera vez vivimos en un mundo en el que no podemos imaginar uno mejor" (ADORNO, 2010, p. 61, mi traducción). Es decir, no es solo que no se pueda concebir el "cómo", sino el "dónde" vivir mejor. De hecho, es justamente ahí donde Adorno rechaza la postura utópica de Bloch, en la medida en que para el frankfurtiano solo la modificación de la totalidad implicaría verdaderamente el inicio de la posibilidad de la realización de la utopía. ¿Significa esto un bloqueo de la praxis? La labor del filósofo no debe ser "decir a los demás lo que tienen que hacer", sino dar herramientas para "modificar su consciencia", dar herramientas para hacer que el lector "vislumbre la idea de que el cambio es posible" (Ibídem). Sobre este asunto se ocupó Adorno con gran intensidad en sus lecciones sobre filosofía moral de 1963, las cuales complejizan aún más sus planteamientos sobre el sujeto. Adorno parece que está, de nuevo, pensando en paralelo a su 
teoría del conocimiento. Para él, las contradicciones de lo real no pueden disolverse mediante una articulación que trate de hacerlas desaparecer, sino enfrentarse a tal contradicción (Cfr. ADORNO, 1997, p. 21). En cualquier caso esto, para Habermas, implica la primacía de la filosofía de la reflexión, que "entiende el proceso de formación del espíritu (conforme al modelo de la relación del sujeto consigo mismo) como un proceso por el que el espíritu deviene consciente de sí" (HABERMAS, 1993, p. 84). Su modelo de "autoilustración" tiene su base en el modelo del acuerdo, que es, a su juicio, por fuerza racional (Cfr. HABERMAS, 1987, p. 27-28). Para Habermas, "los juegos lingüísticos que funcionan [...] descansan sobre un trasfondo de consenso" que, a su vez, necesita del "reconocimiento" del interlocutor como tal para alcanzarse (Ibídem, p. 28). Es decir, Habermas propone un marco de ideal que habría que alcanzar: tal sería su modelo de ilustración, de "autorrealización cooperativa". Por eso, trata de corregir a Adorno y encuentra en la "intersubjetividad no menoscabada" la clave para comprender sus conceptos de "reconciliación" y "libertad". Precisamente donde Adorno se detiene, donde ni siquiera es posible imaginar la alternativa a la vida falsa, Habermas pone la acción comunicativa. Para él, en la comunicación se esconde, al menos, un principio primario de intersubjetividad, de búsqueda de la validez y del reconocimiento del otro. A diferencia de Adorno, que considera que en las relaciones personales se repiten los modelos de la producción industrializada, Habermas defiende que no hay necesariamente una repetición de los modelos de intercambio con las relaciones interpersonales (Cfr. MULLEN, 2016, p. 79). Parecería, sin embargo, que Habermas no ha jugado limpio. Adorno no simplifica meramente razón a "razón instrumental" ni imposibilita la comunicación. Precisamente, el potencial de Adorno se encontraría en la aceptación de los límites del sujeto. El modelo de ilustración en Adorno no se enfocaría, como en Habermas, en reformular la racionalidad, sino de relativizar su fuerza. Adorno, sobre todo, asume los límites del sujeto y rechaza la "reductio ad hominen" y su inversa, la "reductio hominis" (ADORNO, 1984, p. 184 y 268). Para él, retrospectivamente, la comunicación cotidiana que 
| 150 |

Las manos sucias de la Teoría Crítica:..

abandera Habermas sería la repetición en la acción de un defecto de la teoría, a saber, la de la conversión de la intersubjetividad en un nuevo sujeto. Es decir, no se lograría en la acción comunicativa la única salida a una praxis no adaptativa en Adorno: sino en la primacía del objeto. Ésta apunta, precisamente, a lo otro en un sentido enfático, a la puesta en jaque de todos los modelos tradicionales de conocer, más o menos racionales. No propone otra racionalidad, pues terminaría, a su juicio, cosificándose y endureciéndose. Él va más atrás, y pone en jaque al propio modelo racional: de ahí su interés por otras formas de conocimiento, como las generadas en el plano artístico. Es por eso que Adorno defiende lo aún-no-pensado, lo no contemplado ni por la teoría de la praxis, que él cifra como espontaneidad, como "inadecuado" [unangemessen], es decir, no adaptado. Para él, cuando una situación se ha vuelto insoportable, no seguir colaborando, no seguir jugando al juego, es donde se sitúa el eje teoría-praxis más radical.

\section{Referencias}

ADORNO, T. W. Dialéctica negativa. Trad. José M. Ripalda. Madrid: Taurus, 1984.

1993.

Consignas. Trad. Ramón Bilbao. Buenos Aires: Amorrortu, 1997.

Probleme der Moralphilosophie. Frankfurt: Suhrkamp,

Dialéctica negativa. Jerga de la autenticidad. Trad. A. B. Muñoz. Madrid: Akal, 2005.

Crítica de la cultura y la sociedad II. Trad. J. N. Pérez. Madrid: Akal, 2008.

Filosofía de la nueva música. Trad. Alfredo B. Muñoz. Madrid: Akal, 2011. 
ADORNO, T. W.; HORKHEIMER, M. Towards a New Manifesto. New Left Review, 65, p. 33-61, 2010.

BUCK-MORSS, S. The Origin of Negative Dialectics: Theodor W. Adorno, Walter Benjamin and the Frankfurt Institute. Nueva York: Macmillan, 1977.

DENEEN, P. J. The Odyssey of Political Theory: The Politics of Departure and Return. Lanham, MD: Rowman and Littlefield, 2003.

DEWS, P. (ed.). Autonomy and Solidarity: Interviews with Jürgen Habermas. Londres-Nueva York: Verso, 1992.

FEENBERG, A. Realizing Philosophy: Marx, Lukács and the Frankfurt School. In: LUDOVISI, S. G. (ed.). Critical Theory and the Challenge of Praxis: Beyond Reification. Surrey-Burlington: Ashgate, 2015, p. 117-130.

FINLAYSON, J. G. The Question of Praxis in Adorno's Critical Theory. In: LUDOVISI, S. G. (ed.). Critical Theory and the Challenge of Praxis: Beyond Reification. Surrey-Burlington: Ashgate, 2015, p. 51-68.

HABERMAS, J. Perfiles filosófico-políticos. Trad. Manuel Jiménez Redondo. Madrid: Taurus, 1975.

Tecnos, 1987.

Teoría y praxis. Trad. S. M. Torres y C. M. Espí. Madrid:

El discurso filosófico de la modernidad. Trad. Manuel Jiménez Redondo. Madrid: Taurus, 1993.

Teoría de la acción comunicativa, vol. I. Trad. Manuel Jiménez Redondo. Madrid: Taurus, 1999.

Verdad y justificación. Trad. Pere Fabra y Luis Díez. Madrid: Trotta, 2002.

HEGEL, G. W. F. Rasgos fundamentales de la filosofía del derecho. Trad. Eduardo Vásquez. Madrid: Biblioteca Nueva, 2000. 
| 152 |

Las manos sucias de la Teoría Crítica:..

HOLLOWAY, J.; MATAMOROS, F.; TISCHLER, S. Negativity and Revolution: Adorno and Political Activism. Londres: Pluto, 2009.

HONNETH, A. Patologías de la razón: Historia y actualidad de la teoría crítica. Trad. Griselda Mársico. Madrid: Katz, 2009.

HORKHEIMER, M. Crítica de la razón instrumental. Trad. Héctor Álvarez Murena y David Vogelmann. Buenos Aires: Sur, 1973.

MULLEN, G. A. Adorno on Politics after Auschwitz. London: Lexington Books, 2016.

PLATON. Diálogos IV: República. Trad. Conrado Eggers Lan. Madrid: Gredos, 1988.

VELASCO, J. C. Para leer a Habermas. Madrid: Alianza, 2014.

WELLMER, A. Comunicación y emancipación: Reflexiones sobre el "giro lingüístico" de la Teoría Crítica. Trad. Francisco Colom García. Isegoría, 1, 1990. 